\title{
IKERLANAK
}

\section{MONOPOLY PRICE DISCRIMINATION WITH CONSTANT ELASTICITY DEMAND}

by

Iñaki Aguirre and Simon G. Cowan

2013

Working Paper Series: IL. 74/13

Departamento de Fundamentos del Análisis Económico I

Ekonomi Analisiaren Oinarriak I Saila

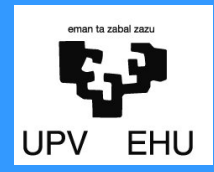

University of the Basque Country 


\title{
Monopoly Price Discrimination with Constant Elasticity Demand*
}

\author{
Iñaki Aguirre ${ }^{\dagger}$ \\ University of the Basque Country UPV/EHU \\ Simon G. Cowan ${ }^{\ddagger}$ \\ University of Oxford
}

November 2013

\begin{abstract}
This paper presents new results on the welfare effects of thirddegree price discrimination under constant elasticity demand. We show that when both the share of the strong market under uniform pricing and the elasticity difference between markets are high enough, then price discrimination not only can increase social welfare but also consumer surplus. (JEL D42, L12, L13)
\end{abstract}

*Financial support from the Ministerio de Economía y Competitividad (ECO201231626), and from the Departamento de Educación, Política Linguiística y Cultura del Gobierno Vasco (IT869-13) is gratefully acknowledged. We would like to thank Ilaski Barañano and Ignacio Palacios-Huerta for helpful comments.

†Departamento de Fundamentos del Análisis Económico I and BRiDGE Group, University of the Basque Country UPV/EHU, Avda. Lehendakari Aguirre 83, 48015-Bilbao, Spain, e-mail: inaki.aguirre@ehu.es.

† Department of Economics, University of Oxford, Manor Road Building, Manor Road, Oxford OX1 3UQ, UK, e-mail: simon.cowan@economics.ox.ac.uk. 


\section{Introduction}

Understanding the conditions under which the change in social welfare can be signed when moving from uniform pricing to price discrimination has concerned economists at least from the earlier work of Pigou (1920) and Robinson (1933). Since third-degree price discrimination is viewed as an inefficient way of distributing a given quantity of output between different consumers or submarkets, an increase in total output is a necessary condition for price discrimination to increase social welfare (Robinson, 1933, Ippolito, 1980, Schmalensee, 1981, Varian, 1985, Schwartz, 1990, and Bertoletti, 2004). So a focal point in the literature has been the analysis of the effects of price discrimination on output: in the case of linear demand price discrimination does not change output when all markets are served (Pigou, 1920, and Robinson, 1933), but in the general non-linear case the effect of price discrimination on output and, therefore, on welfare may be either positive or negative. ${ }^{1}$

Since Robinson (1933) much research has studied the effects of price discrimination on output and social welfare. Unfortunately, however, one of the most popular demand families, constant elasticity demand, has proven particularly resistant to analysis. In particular, the general criteria developed in the literature for characterizing the circumstances under which third-degree price discrimination increases output and/or social welfare are unable to answer two simple questions:

(i) does price discrimination always increase total output under constant demand elasticity conditions? ${ }^{2}$

\footnotetext{
${ }^{1}$ A great many papers have addressed this issue, including Leontief (1940), Edwards (1950), Silberberg (1970), Greenhut and Ohta (1976), Smith and Formby (1981), Schmalensee (1981), Varian (1985), Shih, Mai and Liu (1988), Cheung and Wang (1994) and, more recently, Cowan (2007), Aguirre, Cowan and Vickers (2010) (ACV) and Cowan (2012).

${ }^{2}$ Neither the "adjusted concavity" criterion (Robinson, 1933, Cheung and Wang, 1994), nor the "slope ratio" criterion (Edwards, 1950), nor the "mean-value theorem" criterion (Shih, Mai and Liu, 1988), can be applied to illustrate that price discrimination increases total output with constant elasticity demand. On the other hand, ACV (2010) states that if both the inverse and direct demands in the weak market (the market where price decreases with price discrimination) are more convex than in the strong market (the market where price increases with discrimination) then total output rises. Unfortunately, under constant elasticity demand this sufficient condition for output increasing cannot be applied because the direct demand is more convex in the weak market than in the strong market, while the inverse demand is more convex in the strong market.
} 
(ii) when does price discrimination increase social welfare with constant demand elasticity?

For the first question, Aguirre (2006) proves that total output is higher with discrimination (using an inequality due to Bernoulli), and ACV (2010) present a slightly easier and more intuitive proof. ${ }^{3}$ ACV (2010), using a similar technique to that used to show that output increases, prove a negative result: if the difference between the elasticities is less than one then social welfare falls with discrimination. This technique, however, seems to be unable to produce sufficient conditions for welfare to rise. ${ }^{4}$

The general welfare analyses by Schmalensee (1981), Varian (1985), ACV (2010) and Cowan (2012) do not seem to yield anything of interest for the case of constant elasticity demand. For example, Varian (1985) states upper and lower bounds to the welfare change when moving from unifom pricing to price discrimination based on the concavity of the utility function. The upper bound provides a necessary condition for price discrimination to increase welfare (an increase in output), and the lower bound provides a sufficient condition. Under constant elasticity demand the upper bound is positive whereas the lower bound can be positive or negative depending on the parameters. Consequently, Varian's analysis does not allow us to reach a definite conclusion. ACV (2010) follow the method of considering the effects of a continuous movement from uniform pricing to price discrimination. Initially the firm is not allowed (or is unable) to discriminate and hence sets the uniform price. Then the constraint on the firm's freedom to discriminate is gradually relaxed until the firm can discriminate as much as it likes. Their approach is to calculate the marginal effect on welfare generated by relaxing the constraint; if this keeps the same sign as more discrimination is allowed, then the overall effect of discrimination can be obtained. Unfortunately, however, under constant elasticity welfare rises initially as the degree of discrimination increases, and then falls (see their proposition 3), and it is not possible to

\footnotetext{
${ }^{3}$ There is some previous research. Greenhut and Ohta (1976) show through a numerical example that price discrimination may increase output with constant elasticity demands. Ippolito (1980) obtains the result via numerical simulations that total output increases under third-degree price discrimination in the two-market case. Formby, Layson and Smith (1983) using Lagrangean techniques show that monopolistic price discrimination increases total output over a wide range of constant elasticities.

${ }^{4}$ Using numerical simulations Ippolito (1980) shows that the effect of third-degree price discrimination is undetermined and more likely to be positive when both the difference between elasticities and the share of the strong market are high enough.
} 
state whether the effect on welfare of full discrimination is positive or negative. Cowan (2012) shows that aggregate consumer surplus is higher with discrimination (which constitutes a sufficient condition for an increase in social welfare) if the ratio of pass-through (which is the ratio of the slope of the inverse demand to the slope of marginal revenue) to the price elasticity at the uniform price is at least as high in the weak market as in the strong market. ${ }^{5}$ However, once again, his analysis does not allow us to reach any definite conclusions with constant elasticity.

This paper presents new results on the welfare effects of third-degree price discrimination under constant elasticity demand. We show that when both the share of the strong market under uniform pricing and the elasticity difference are high enough then third-degree price discrimination increases social welfare. Moreoever, consumer surplus can also increase but, as expected, under more stringent conditions. We also relate the effect of price discrimination on consumer surplus to the Varian's lower bound under constant elasticity demand. In particular, we are able to obtain new lower bounds for the welfare change that provides both new sufficient conditions and necessary conditions for strictly log-convex demand curves.

We begin in Section II with a standard model of third-degree price discrimination with two markets whose demands exhibit constant price-elasticity. In Section III, we analyze the effects of a move from uniform pricing to price discrimination on social welfare and, in Section IV, we study the effects on consumer surplus. Section V generalizes a property satisfied by constant elasticity demands to obtain new upper and lower bounds on social welfare when demand functions are log-convex. Finally Section VI presents some conclusions.

\footnotetext{
${ }^{5}$ See Weyl and Fabinger (2013) for an extensive analysis of pass-through.
} 


\section{The model}

Consider a monopolist selling a good in two perfectly separated markets. The demand function in market $i$ has constant price-elasticity $D_{i}\left(p_{i}\right)=$ $a_{i}\left(p_{i}\right)^{-\varepsilon_{i}}$, where $\varepsilon_{i}>1$ is the constant elasticity and $a_{i}>0, i=1,2$, is a measure of market size. We assume that the demand elasticity is greater in market 2: $\varepsilon_{2}=\varepsilon_{1}+\theta$ where $\theta>0$. Unit cost is assumed to be constant, $c>0$. The profit function in market $i, i=1,2$, is given by $\pi_{i}\left(p_{i}\right)=\left(p_{i}-c\right) D_{i}\left(p_{i}\right)=\left(p_{i}-c\right) a_{i}\left(p_{i}\right)^{-\varepsilon_{i}}$. Note that this profit function is not overall concave and its concavity actually changes at a price $\bar{p}_{i}=\frac{\left(\varepsilon_{i}+1\right)}{\left(\varepsilon_{i}-1\right)} c$ (see also Nahata, Ostaszewski and Sahoo, 1990):

$$
\pi_{i}^{\prime \prime}\left(p_{i}\right)=\left\{\begin{array}{cr}
<0 & p_{i}<\frac{\left(\varepsilon_{i}+1\right)}{\left(\varepsilon_{i}-1\right)} c \\
=0 & p_{i}=\frac{\left(\varepsilon_{i}+1\right)}{\left(\varepsilon_{i}-1\right)} c=\bar{p}_{i} \\
>0 & p_{i}>\frac{\left(\varepsilon_{i}+1\right)}{\left(\varepsilon_{i}-1\right)} c
\end{array}\right\} .
$$

The profit function in market $i$ is, however, single-peaked and reaches a unique maximum at:

$$
p_{i}^{*}=\frac{\varepsilon_{i}}{\varepsilon_{i}-1} c
$$

which is the optimal price in market $i, i=1,2$, under third-degree price discrimination. The quantity sold in market $i, i=1,2$, is:

$$
q_{i}^{*}=a_{i}\left(\frac{\varepsilon_{i}}{\varepsilon_{i}-1} c\right)^{-\varepsilon_{i}}
$$

and total output is:

$$
q^{*}=\sum_{i=1}^{2} a_{i}\left(\frac{\varepsilon_{i}}{\varepsilon_{i}-1} c\right)^{-\varepsilon_{i}}
$$


Under simple monopoly pricing, the profit function is given by $\pi(p)=$ $\pi_{1}(p)+\pi_{2}(p)=(p-c) \sum_{i=1}^{2} D_{i}(p)=(p-c) \sum_{i=1}^{2} a_{i}(p)^{-\varepsilon_{i}}$. Although this profit function is not always quasi-concave, from Theorem 1 by Nahata, Ostaszewski and Sahoo (1990) we state that the optimal uniform price, $p^{0}$, is such that $p_{1}^{*}>p^{0}>p_{2}^{*}$ and satisfies the following first order condition

$$
\pi^{\prime}\left(p^{0}\right)=\pi_{1}^{\prime}\left(p^{0}\right)+\pi_{2}^{\prime}\left(p^{0}\right)=\sum_{i=1}^{2} D_{i}\left(p^{0}\right)+\left(p^{0}-c\right) \sum_{i=1}^{2} D_{i}^{\prime}\left(p^{0}\right)=0 .
$$

The second derivative of the profit function is given by:

$$
\pi^{\prime \prime}(p)=\pi_{1}^{\prime \prime}(p)+\pi_{2}^{\prime \prime}(p)=2\left[D_{1}^{\prime}(p)+D_{2}^{\prime}(p)\right]+(p-c)\left[D_{1}^{\prime \prime}(p)+D_{2}^{\prime \prime}(p)\right],
$$

which under constant elasticity demand becomes:

$$
\begin{gathered}
\pi^{\prime \prime}(p)=\varepsilon_{1} a_{1} p^{-\left(\varepsilon_{1}+1\right)}\left[\left(\varepsilon_{1}-1\right)-\frac{\left(\varepsilon_{1}+1\right) c}{p}\right] \\
+\varepsilon_{2} a_{2} p^{-\left(\varepsilon_{2}+1\right)}\left[\left(\varepsilon_{2}-1\right)-\frac{\left(\varepsilon_{2}+1\right) c}{p}\right] .
\end{gathered}
$$

The aggregate profit function is not necessarily quasi-concave and, therefore, might have several peaks (local maxima). The aggregate profit function would be concave (and therefore quasi-concave) in the relevant range of prices if $\pi^{\prime \prime}(p)<0 \forall p \in\left[p_{2}^{*}, p_{1}^{*}\right]$. Note that $\pi^{\prime \prime}(p)<0$ for all $p \in\left[p_{2}^{*}, \bar{p}_{2}\right]$ given the shape of the profit function in market 2 (see condition (1)). Therefore, a sufficient condition for concavity of the profit function is $p_{1}^{*} \leq \bar{p}_{2}$ or, alternatively, $\varepsilon_{2} \leq 2 \varepsilon_{1}-1$ (see conditions 1 and 2 ).

Under constant elasticity all markets are served under uniform pricing. Note that $D_{2}\left(p_{1}^{*}\right)>0$, which guarantees that the firm is always wishing to serve the more elastic demand. The Lerner index is given by: 


$$
\frac{p^{0}-c}{p^{0}}=\frac{1}{\varepsilon\left(p^{0}\right)}
$$

where $p^{0}$ denotes the uniform price and $\varepsilon\left(p^{0}\right)$ is the elasticity of the aggregate demand at $p^{0}$. Let $D(p)=\sum_{i=1}^{2} D_{i}(p)$ denote the aggregate demand. From the first-order condition (5) this elasticity is the weighted average elasticity:

$$
\varepsilon\left(p^{0}\right)=\sum_{i=1}^{2} \alpha_{i}\left(p^{0}\right) \varepsilon_{i}\left(p^{0}\right)=\frac{\sum_{i=1}^{2} \varepsilon_{i} a_{i}\left(p^{0}\right)^{-\varepsilon_{i}}}{\sum_{i=1}^{2} a_{i}\left(p^{0}\right)^{-\varepsilon_{i}}}
$$

where the elasticity of market $i$ is weighted by the "share" of that market at the optimal uniform price, $\alpha_{i}\left(p^{0}\right)=D_{i}\left(p^{0}\right) / \sum_{i=1}^{2} D_{i}\left(p^{0}\right)$. The quantity sold in each market and the total output are respectively given by:

$$
q_{i}^{0}=a_{i}\left(p^{0}\right)^{-\varepsilon_{i}}, i=1,2, \text { and } q^{0}=\sum_{i=1}^{2} a_{i}\left(p^{0}\right)^{-\varepsilon_{i}}
$$

The change in the quantity sold in market $i$ due to a move from uniform pricing to third-degree price discrimination is given by:

$$
\Delta q_{i}=q_{i}^{*}-q_{i}^{0}=a_{i}\left[\left(\frac{\varepsilon_{i}}{\varepsilon_{i}-1} c\right)^{-\varepsilon_{i}}-\left(p^{0}\right)^{-\varepsilon_{i}}\right], i=1,2 .
$$

Therefore, price discrimination decreases output in market 1 and increases output in market 2: $\Delta q_{1}<0$ and $\Delta q_{2}>0$. The effect of third-degree price discrimination on social welfare depends crucially on the change in the total output:

$$
\Delta q=q^{*}-q^{0}=\Delta q_{1}+\Delta q_{2}=\sum_{i=1}^{2} a_{i}\left[\left(\frac{\varepsilon_{i}}{\varepsilon_{i}-1} c\right)^{-\varepsilon_{i}}-\left(p^{0}\right)^{-\varepsilon_{i}}\right]
$$


Following Formby, Layson and Smith (1983) and Aguirre (2006) we assume that the units of production are defined so that $p^{0}=1$. Therefore, the elasticity of the market demand, the quantity sold in each market and the total output are respectively given by:

$$
\varepsilon(1)=\frac{\sum_{i=1}^{2} \varepsilon_{i} a_{i}}{\sum_{i=1}^{2} a_{i}} ; q_{i}^{0}=a_{i} \text { and } q^{0}=\sum_{i=1}^{2} a_{i}, i=1,2
$$

Given condition (4) and the normalization $p^{0}=1$, the marginal cost is given by:

$$
c=\frac{\sum_{i=1}^{2} a_{i}\left(\varepsilon_{i}-1\right)}{\sum_{i=1}^{2} a_{i} \varepsilon_{i}} .
$$

Total output at the uniform price is $a_{1}+a_{2}$. Define $\alpha=\frac{a_{1}}{a_{1}+a_{2}}$ as the share of market 1 and $1-\alpha=\frac{a_{2}}{a_{1}+a_{2}}$ as the share of market 2 under uniform pricing. We assume without loss of generality that $a_{1}+a_{2}=1$. Equation (13) may then be written as:

$$
c=\frac{a_{1}\left(\varepsilon_{1}-1\right)+a_{2}\left(\varepsilon_{2}-1\right)}{a_{1} \varepsilon_{1}+a_{2} \varepsilon_{2}}=\frac{\varepsilon_{1}+(1-\alpha) \theta-1}{\varepsilon_{1}+(1-\alpha) \theta} .
$$

We restrict our analysis to configurations of market elasticities such that the aggregate profit function reaches its maximum at $p^{0}=1$; Assumption 1 states the associated range of demand elasticities, $\varepsilon_{1}$ and $\varepsilon_{1}+\theta$.

Assumption 1. The elasticity difference belongs to an interval $\left[0, \widetilde{\theta}\left(\varepsilon_{1}\right)\right]$ such that $p^{0}=1$ is the global maximizer under uniform pricing.

Assumption 1 allows the aggregate profit function not to be quasi-concave (that is, it might have several peaks) but, even though there may exist several local maxima, $p^{0}=1$ is the global maximizer.

The critical value for the elasticity difference, $\tilde{\theta}\left(\varepsilon_{1}\right)$, depends also on $\alpha$. For simplicity we define $\widetilde{\theta}\left(\varepsilon_{1}\right)$ as the higher elasticity difference such that 
$p^{0}=1$ is the global maximum regardless of the value of $\alpha \cdot{ }^{6}$ As Table 1 (see the Appendix) illustrates the range of elasticity difference such that $p^{0}=1$ is the global maximizer is much wider than the range of values of $\theta$ such that $\theta<\varepsilon_{1}-1$, which is the condition that is sufficient for concavity. Note also that $\theta\left(\varepsilon_{1}\right)$ is an increasing function of $\varepsilon_{1}$.

\section{Welfare effects of price discrimination}

A move from uniform pricing to price discrimination generates a welfare change of: ${ }^{7}$

$$
\Delta W=\Delta u_{1}+\Delta u_{2}-c \Delta q
$$

where $\Delta u_{1}=u_{1}\left(q_{1}^{*}\right)-u_{1}\left(q_{1}^{0}\right), \Delta u_{2}=u_{2}\left(q_{2}^{*}\right)-u_{2}\left(q_{2}^{0}\right)$ and $\Delta q=\Delta q_{1}+\Delta q_{2}$. We can rewrite the change in social welfare as:

$$
\begin{aligned}
\Delta W & =\int_{q_{1}^{0}}^{q_{1}^{*}}\left[p_{1}(q)-c\right] d q+\int_{q_{2}^{0}}^{q_{2}^{*}}\left[p_{2}(q)-c\right] d q, \\
& =\int_{q_{1}^{0}}^{q_{1}^{*}}\left[a_{1}^{\frac{1}{\varepsilon_{1}}}(q)^{-\frac{1}{\varepsilon_{1}}}-c\right] d q+\int_{q_{2}^{0}}^{q_{2}^{*}}\left[a_{2}^{\frac{1}{\varepsilon_{2}}}(q)^{-\frac{1}{\varepsilon_{2}}}-c\right] d q,
\end{aligned}
$$

that is, the change in welfare is the sum across markets of the cumulative difference between price and marginal cost for each market between the output under single pricing and the output under price discrimination. As output decreases in the strong market and increases in the weak market, the first

\footnotetext{
${ }^{6}$ For example, when $\varepsilon_{1}=4$ if the elasticity difference is $\theta=17$ then for $\alpha \in(0,0.797) \cup$ $(0.9,0.999)$ the global maximum is $p=1$. When $\alpha \in(0.797,0.9)$ the optimal uniform price can be higher or lower than $p=1$. As Table 1 indicates when $\varepsilon_{1}=4$ and $\theta \in(0,16.9]$ then the aggregate profit function reaches a global maximum at $p=1$.

${ }^{7} \mathrm{We}$ consider the case of quasilinear-utility function with an aggregate utility function of the form $\sum_{i=1}^{2}\left[u_{i}\left(q_{i}\right)+y_{i}\right]$, where $q_{i}$ is consumption in submarket $i$ and $y_{i}$ is the amount to be spent on other consumption goods, $i=1,2$. It is assumed that $u_{i}^{\prime}>0$ and $u_{i}^{\prime \prime}<0$, $i=1,2$.
} 
term in (16) is the welfare loss in market 1 , whereas the second term is the welfare gain in market $2 .^{8}$ We may write the change in social welfare in terms of $\varepsilon_{1}, \alpha$ and $\theta$ as:

$$
\begin{aligned}
& \Delta W\left(\varepsilon_{1}, \alpha, \theta\right)= \frac{\alpha}{\varepsilon_{1}-1}\left[\left(\frac{\varepsilon_{1}-1}{\varepsilon_{1}} \frac{\varepsilon_{1}+(1-\alpha) \theta}{\varepsilon_{1}+(1-\alpha) \theta-1}\right)^{\left(\varepsilon_{1}-1\right)} \frac{\left(2 \varepsilon_{1}-1\right)}{\varepsilon_{1}}\right] \\
&+\frac{(1-\alpha)}{\varepsilon_{1}+\theta-1}\left[\left(\frac{\varepsilon_{1}+\theta-1}{\varepsilon_{1}+\theta} \frac{\varepsilon_{1}+(1-\alpha) \theta}{\varepsilon_{1}+(1-\alpha) \theta-1}\right)^{\left(\varepsilon_{1}+\theta-1\right)} \frac{\left(2 \varepsilon_{1}+2 \theta-1\right)}{\varepsilon_{1}+\theta}\right] \\
&-\frac{1}{\varepsilon_{1}+(1-\alpha) \theta}-\frac{\alpha}{\varepsilon_{1}-1}-\frac{(1-\alpha)}{\varepsilon_{1}+\theta-1} .
\end{aligned}
$$

Although it is well-known that third-degree price discrimination increases total output, not much is known about its effect on social welfare. The next proposition reviews previously known results:

\section{Proposition 1.}

(i) Total output increases with third-degree price discrimination.

(ii) If the difference in the submarkets elasticities is small enough, $\theta \leq 1$, then the change in social welfare is negative for any $\varepsilon_{1}$ and $\alpha$.

Proof. See ACV (2010).

Therefore a necessary condition for price discrimination to increase social welfare is $\theta>1$. (As ACV, 2010, show the condition in part (ii) of the proposition can be relaxed to $\theta \alpha \leq 1$ : when the elasticity difference does not exceed the reciprocal of the share of the strong market in total output at the nondiscriminatory price then price discrimination reduces social welfare).

The next lemma states properties of the relationship between the change in social welfare, $\Delta W$, and the share of the strong market under uniform pricing, $\alpha$.

\footnotetext{
${ }^{8}$ The overall effect on welfare may be positive or negative. See ACV (2010) for sufficient conditions based on the shape of the demand and inverse demand functions to determine the sign of the welfare effect. Unfortunately, under constant elasticity demand those sufficient conditions are not satisfied.
} 
Lemma 1. Given $\varepsilon_{1}$ and $\theta$ :

(i) The change in social welfare $\Delta W$ is a continuous function of $\alpha$.

(ii) Single-crossing property: $\Delta W\left(\varepsilon_{1}, \alpha, \theta\right)$ crosses at most once the $\Delta W=0$ axis. That is, there exists at most one value $\alpha \in(0,1)$ such that $\Delta W=0$.

Proof. (i) It follows from condition (17). (ii) The change in social welfare is a convex-concave function of $\alpha$ (by this we mean that there exists $\widetilde{\alpha} \in(0,1)$ such that $\Delta W$ is convex for $\alpha<\widetilde{\alpha}$ and concave for $\alpha>\widetilde{\alpha}$ ) given that the second derivative with respect to $\alpha$ has the single-crossing property (see the Appendix $).{ }^{9}$ Note that since $\Delta W\left(\varepsilon_{1}, \alpha=0, \theta\right)=0$ and $\Delta W\left(\varepsilon_{1}, \alpha=1, \theta\right)=0$ then as the change in social welfare is a convex-concave function then it is guaranteed that the single-crossing property is satisfied. $\square$

We next consider the effect on the change in social welfare of a small change in the share of the strong market under uniform pricing. The derivative of the change in social welfare, $\Delta W$, with respect to the share of the strong market, $\alpha$, is given by:

$$
\begin{gathered}
\frac{\partial\left(\Delta W\left(\varepsilon_{1}, \alpha, \theta\right)\right)}{\partial \alpha}=\frac{1}{\varepsilon_{1}-1} \frac{\left(2 \varepsilon_{1}-1\right)}{\varepsilon_{1}}\left[\frac{\left(\varepsilon_{1}-1\right)}{\varepsilon_{1}} \frac{1}{c}\right]^{\left(\varepsilon_{1}-1\right)} \\
+\frac{\alpha}{\varepsilon_{1}}\left(2 \varepsilon_{1}-1\right)\left(\frac{\varepsilon_{1}-1}{\varepsilon_{1}} \frac{\theta}{\left[\varepsilon_{1}+(1-\alpha) \theta-1\right]^{2}}\right)\left[\frac{\left(\varepsilon_{1}-1\right)}{\varepsilon_{1}} \frac{1}{c}\right]^{\left(\varepsilon_{1}-2\right)} \\
-\frac{1}{\varepsilon_{1}+\theta-1} \frac{\left(2 \varepsilon_{1}+2 \theta-1\right)}{\varepsilon_{1}+\theta}\left[\frac{\left(\varepsilon_{1}+\theta-1\right)}{\varepsilon_{1}+\theta} \frac{1}{c}\right]^{\left(\varepsilon_{1}+\theta-1\right)} \\
+\frac{(1-\alpha)\left(2 \varepsilon_{1}+2 \theta-1\right)}{\varepsilon_{1}+\theta}\left(\frac{\varepsilon_{1}+\theta-1}{\varepsilon_{1}+\theta} \frac{1}{\left[\varepsilon_{1}+(1-\alpha) \theta-1\right]^{2}}\right)\left[\frac{\left(\varepsilon_{1}+\theta-1\right)}{\varepsilon_{1}+\theta} \frac{1}{c}\right]^{\left(\varepsilon_{1}+\theta-2\right)} \\
-\frac{1}{\left[\varepsilon_{1}+(1-\alpha) \theta\right]^{2}}-\frac{1}{\varepsilon_{1}-1}+\frac{1}{\varepsilon_{1}+\theta-1} .
\end{gathered}
$$

where $c=\frac{\varepsilon_{1}+(1-\alpha) \theta-1}{\varepsilon_{1}+(1-\alpha) \theta}$.

\footnotetext{
${ }^{9}$ The considerations on the single-crossing property are based on Quah and Strulovici (2012).
} 
By evaluating condition (18) at $\alpha=1$ we get:

$$
\begin{gathered}
\frac{\partial\left(\Delta W\left(\varepsilon_{1}, \alpha=1, \theta\right)\right)}{\partial \alpha}=\frac{1}{\varepsilon_{1}}+\frac{\theta}{\varepsilon_{1}\left(\varepsilon_{1}-1\right)}+\frac{1}{\varepsilon_{1}+\theta-1} \\
-\frac{1}{\varepsilon_{1}+\theta-1} \frac{\left(2 \varepsilon_{1}+2 \theta-1\right)}{\varepsilon_{1}+\theta}\left(\frac{\varepsilon_{1}+\theta-1}{\varepsilon_{1}+\theta} \frac{\varepsilon_{1}}{\varepsilon_{1}-1}\right)^{\left(\varepsilon_{1}+\theta-1\right)} .
\end{gathered}
$$

We denote as $\underline{\theta}\left(\varepsilon_{1}\right)$ the elasticity difference such that $\frac{\partial\left(\Delta W\left(\varepsilon_{1}, \alpha=1, \underline{\theta}\left(\varepsilon_{1}\right)\right)\right)}{\partial \alpha}=$ 0 . From numerical computations (see Appendix) we obtain that the cross derivative $\frac{\partial^{2}\left(\Delta W\left(\varepsilon_{1}, \alpha=1, \theta\left(\varepsilon_{1}\right)\right)\right)}{\partial \alpha \partial \theta}$ is such that:

$$
\frac{\partial^{2}\left(\Delta W\left(\varepsilon_{1}, \alpha=1, \theta\left(\varepsilon_{1}\right)\right)\right)}{\partial \alpha \partial \theta}\left\{\begin{array}{ll}
>0 & \text { if } \theta<\widehat{\theta}\left(\varepsilon_{1}\right) \\
=0 & \text { if } \theta=\widehat{\theta}\left(\varepsilon_{1}\right) \\
<0 & \text { if } \theta>\widehat{\theta}\left(\varepsilon_{1}\right)
\end{array}\right\}
$$

where $\widehat{\theta}\left(\varepsilon_{1}\right)<\underline{\theta}\left(\varepsilon_{1}\right)$. This guatantees that $\frac{\partial\left(\Delta W\left(\varepsilon_{1}, \alpha=1, \theta\right)\right)}{\partial \alpha}<0$ if $\theta>\underline{\theta}\left(\varepsilon_{1}\right)$ and $\frac{\partial\left(\Delta W\left(\varepsilon_{1}, \alpha=1, \theta\right)\right)}{\partial \alpha}>0$ if $\widehat{\theta}\left(\varepsilon_{1}\right)<\theta<\underline{\theta}\left(\varepsilon_{1}\right)$. Even though $\frac{\partial^{2}\left(\Delta W\left(\varepsilon_{1}, \alpha=1, \theta\left(\varepsilon_{1}\right)\right)\right)}{\partial \alpha \partial \theta} \geq 0$ for $\theta \leq \widehat{\theta}\left(\varepsilon_{1}\right)$, it can be checked (numerically) that $\frac{\partial\left(\Delta W\left(\varepsilon_{1}, \alpha=1, \theta\left(\varepsilon_{1}\right)\right)\right)}{\partial \alpha}>0$ for $\theta \leq \widehat{\theta}\left(\varepsilon_{1}\right)$. Therefore, we have that:

$$
\frac{\partial\left(\Delta W\left(\varepsilon_{1}, \alpha=1, \theta\right)\right)}{\partial \alpha}\left\{\begin{array}{ll}
>0 & \text { if } \theta<\underline{\theta}\left(\varepsilon_{1}\right) \\
=0 & \text { if } \theta=\underline{\theta}\left(\varepsilon_{1}\right) \\
<0 & \text { if } \theta>\underline{\theta}\left(\varepsilon_{1}\right)
\end{array}\right\} .
$$

On the other hand, the change in social welfare is zero when the share of the strong market equals $1, \Delta W\left(\varepsilon_{1}, \alpha=1, \theta\right)=0$, and given that $\frac{\partial\left(\Delta W\left(\varepsilon_{1}, \alpha=1, \theta\right)\right)}{\partial \alpha}<$ 0 when $\theta>\underline{\theta}\left(\varepsilon_{1}\right)$ then there exists a cutoff value $\bar{\alpha} \equiv \bar{\alpha}\left(\varepsilon_{1}, \theta\right)$ such that if $\alpha>\bar{\alpha}$ then the social welfare increases with price discrimination. Given that the single crossing property is satisfied then when $\alpha<\bar{\alpha}$ price discrimination reduces social welfare. Numerical computations allow us to conclude that $\underline{\theta}^{\prime}\left(\varepsilon_{1}\right)>0$. For example, $\underline{\theta}(1.5)=1.26083, \underline{\theta}(2)=1.31026, \underline{\theta}(3)=1.36163$ and $\underline{\theta}(4)=1.39003$. Note that $\underline{\theta}\left(\varepsilon_{1}\right)<\widetilde{\theta}\left(\varepsilon_{1}\right)$; for example, $\widetilde{\theta}(1.5)=4.4$, 
$\widetilde{\theta}(2)=7, \tilde{\theta}(3)=11.9$ and $\widetilde{\theta}(4)=16.9$ (see Table 1$)$. Note also that $\underline{\theta}\left(\varepsilon_{1}\right)>1$; that is, $\frac{\partial\left(\Delta W\left(\varepsilon_{1}, \alpha=1, \theta\right)\right)}{\partial \alpha}>0$ when $\theta \leq 1$ which implies (given the single crossing property) that price discrimination reduces social welfare when the elasticity difference is not high enough, so the ACV (2010) negative result is a special case of the analysis here.

The following proposition summarizes the results and states that when the difference between demand elasticities is high enough (but not too high in order to ensure that the second order conditions are satisfied) then there exists a cutoff value for the share of the strong market above which thirddegree price discrimination increases social welfare.

Proposition 2. If $\theta \in\left(\underline{\theta}\left(\varepsilon_{1}\right), \widetilde{\theta}\left(\varepsilon_{1}\right)\right]$, then there exists a cutoff value $\bar{\alpha} \equiv$ $\bar{\alpha}\left(\varepsilon_{1}, \theta\right)$ such that:

(i) If $\alpha<\bar{\alpha}$ then price discrimination reduces social welfare.

(ii) If $\alpha=\bar{\alpha}$ then social welfare remains unchanged.

(iii) If $\alpha>\bar{\alpha}$ then price discrimination increases social welfare.

In order to get some insights on this proposition it is useful to decompose the change in welfare into two effects: a misallocation effect $(M E)$ and an output effect $(O E) .{ }^{10}$ By adding and subtracting $u_{2}\left(q_{2}^{0}-\Delta q_{1}\right)$ to condition (15), we can write the change in welfare as:

$$
\Delta W=M E+O E
$$

where

$$
M E=-\left[u_{1}\left(q_{1}^{0}\right)-u_{1}(\underbrace{q_{1}^{0}+\Delta q_{1}}_{q_{1}^{*}})\right]+\left[u_{2}\left(q_{2}^{0}-\Delta q_{1}\right)-u_{2}\left(q_{2}^{0}\right)\right],
$$

and

$$
O E=\left[u_{2}\left(q_{2}^{*}\right)-u_{2}\left(q_{2}^{0}-\Delta q_{1}\right)\right]-c[\underbrace{q_{2}^{*}-\left(q_{2}^{0}-\Delta q_{1}\right)}_{\Delta q}] .
$$

\footnotetext{
${ }^{10}$ We follow the approach of Ippolito (1980) and Aguirre (2008).
} 
$M E$ may be interpreted as the welfare loss due to the transfer of $\left|\Delta q_{1}\right|$ units of production from market 1 to market 2 . $O E$ can be interpreted as the effect of additional output, $\Delta q$, on social welfare. Therefore, the relationship between the two effects depends on the size of $\left|\Delta q_{1}\right|$ relative to $\Delta q$. Figure 1a shows the output changes when $\varepsilon_{1}=2$ as a function of the share of the strong market in total output at the uniform price; it illustrates how when $\theta \leq 1$ the increase in total output is very low relative to the change in output in market 1 in absolute value.

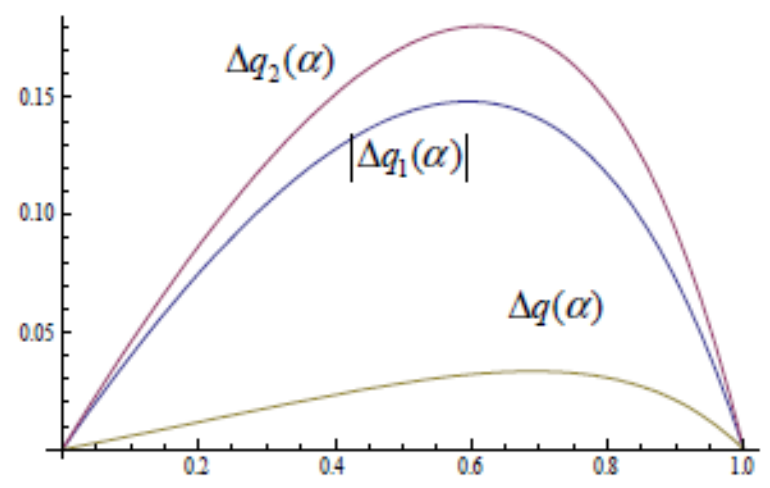

Figure 1a. Output changes as a function of $\alpha$ when $\varepsilon_{1}=2$ and $\theta=0.9$.

When the difference between elasticities across markets increases, the increase in total output is high enough relative to the change in output in market 1 in absolute value. In particular, as Figures $1 \mathrm{~b}$ illustrates, the change in total output can be greater than the change in output (in absolute value) in market 1 when the share of the strong market is high enough (about 0.8); so when the elasticity difference increases then the increase in total output, $\Delta q$, becomes more important relative to the change in output in market 1 in absolute value, $\left|\Delta q_{1}\right|$. 


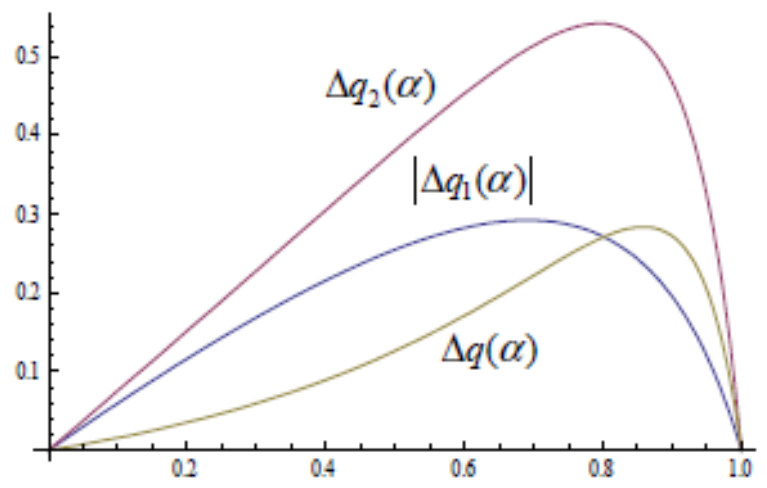

Figure 1b. Output changes as a function of $\alpha$ when $\varepsilon_{1}=2$ and $\theta=3$.

Figure 2 illustrates how the output effect, the misallocation effect and the change in social welfare change with $\alpha$ for the case $\varepsilon_{1}=2$ and $\theta=3$; the cutoff value is $\bar{\alpha}=0.8137$.

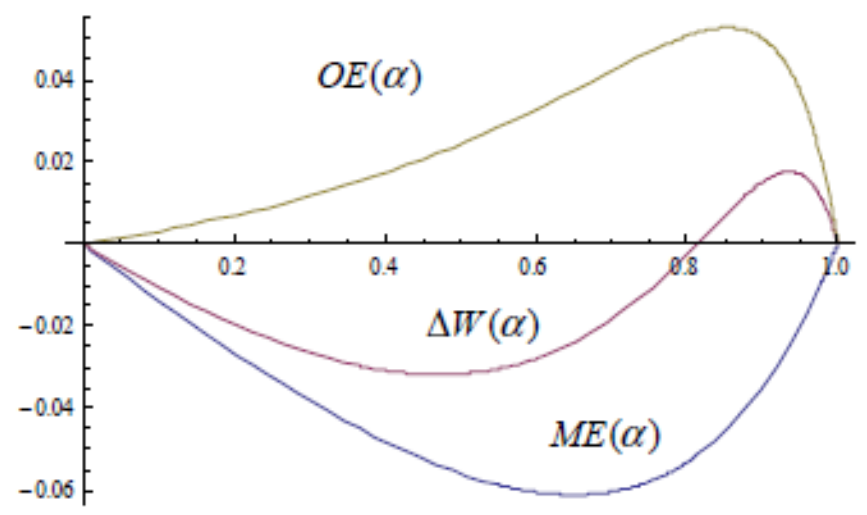

Figure 2. Output effect $(O E)$, misallocation effect $(M E)$ and change in welfare $(\Delta W)$ when $\varepsilon_{1}=2$ and $\theta=3$. Note that the necessary condition $(\alpha \theta>1)$ is satisfied for

$$
\alpha>1 / 3 \text {. }
$$


Table 2 (see Appendix) provides the critical value of the share of market 1 (under single pricing), $\bar{\alpha}\left(\varepsilon_{1}, \theta\right)$, above which the output effect dominates the misallocation effect and, consequently, social welfare increases. Given a high enough elasticity in market 1 (in Table 2 higher than or equal to 3 ), the critical value of the share of market 1 (under single pricing) is a U-shaped function of the elasticity difference. But for a low enough elasticity in market 1 (in Table 3 lower than or equal to 2) the critical value of the share of market 1 (under single pricing) is a decreasing function of the elasticity difference.

Table 3 (see Appendix) shows the critical value for the share of market 1 under uniform pricing as a function of the elasticity ratio and the passthrough ratio (or price ratio). Given an elasticity in market 1, we consider different values for the elasticity in market 2. Table 3 shows that the critical value of the share of market 1 (under single pricing) is a U-shaped function of the elasticity ratio and the pass-through ratio (that is, the ratio of the slope of inverse demand to the slope of marginal revenue).

\section{Effects on consumer surplus}

Consumer surplus in market $i$ corresponding to an output $q_{i}$ can be expressed as: ${ }^{11}$

$$
C S_{i}\left(q_{i}\right)=\int_{0}^{q_{i}}\left[p_{i}(z)-r_{i}^{\prime}(z)\right] d z=\int_{0}^{q_{i}}\left[\frac{p_{i}(z)}{\varepsilon_{i}}\right] d z=\frac{r_{i}\left(q_{i}\right)}{\varepsilon_{i}-1}
$$

where $r_{i}^{\prime}$ and $r_{i}$ denotes marginal revenue and total revenue, respectively. So the change in consumer surplus corresponding to a move from uniform pricing to third-degree price discrimination is:

$$
\Delta C S=\sum_{i=1}^{2} C S_{i}=\sum_{i=1}^{2} \frac{\Delta r_{i}}{\varepsilon_{i}-1}
$$

which becomes:

\footnotetext{
${ }^{11}$ Bulow and Klemperer (2012) shows that consumer surplus equals the area between the inverse demand curve and the marginal revenue curve up to a given quantity.
} 


$$
\begin{gathered}
\Delta C S\left(\varepsilon_{1}, \alpha, \theta\right)=\frac{\alpha}{\varepsilon_{1}-1}\left[\left(\frac{\varepsilon_{1}-1}{\varepsilon_{1}} \frac{\varepsilon_{1}+(1-\alpha) \theta}{\varepsilon_{1}+(1-\alpha) \theta-1}\right)^{\left(\varepsilon_{1}-1\right)}-1\right] \\
+\frac{(1-\alpha)}{\varepsilon_{1}+\theta-1}\left[\left(\frac{\varepsilon_{1}+\theta-1}{\varepsilon_{1}+\theta} \frac{\varepsilon_{1}+(1-\alpha) \theta}{\varepsilon_{1}+(1-\alpha) \theta-1}\right)^{\left(\varepsilon_{1}+\theta-1\right)}-1\right] .
\end{gathered}
$$

Again we consider the effect of a small change in the share of the strong market, $\alpha$, on consumer surplus:

$$
\begin{gathered}
\frac{\partial\left(\Delta C S\left(\varepsilon_{1}, \alpha, \theta\right)\right)}{\partial \alpha}=\frac{1}{\varepsilon_{1}-1}\left[\left(\frac{\left(\varepsilon_{1}-1\right)}{\varepsilon_{1}} \frac{1}{c}\right)^{\left(\varepsilon_{1}-1\right)}-1\right] \\
+\frac{\alpha\left(\varepsilon_{1}-1\right)}{\varepsilon_{1}}\left(\frac{\theta}{\left[\varepsilon_{1}+(1-\alpha) \theta-1\right]^{2}}\right)\left[\frac{\left(\varepsilon_{1}-1\right)}{\varepsilon_{1}} \frac{1}{c}\right]^{\left(\varepsilon_{1}-2\right)} \\
-\frac{1}{\varepsilon_{1}+\theta-1}\left[\left(\frac{\left(\varepsilon_{1}+\theta-1\right)}{\varepsilon_{1}+\theta} \frac{1}{c}\right)^{\left(\varepsilon_{1}+\theta-1\right)}-1\right] \\
+\frac{(1-\alpha)\left(\varepsilon_{1}+\theta-1\right)}{\varepsilon_{1}+\theta}\left(\frac{\theta}{\left[\varepsilon_{1}+(1-\alpha) \theta-1\right]^{2}}\right)\left[\frac{\left(\varepsilon_{1}+\theta-1\right)}{\varepsilon_{1}+\theta} \frac{1}{c}\right]^{\left(\varepsilon_{1}+\theta-2\right)}
\end{gathered}
$$

where $c=\frac{\varepsilon_{1}+(1-\alpha) \theta-1}{\varepsilon_{1}+(1-\alpha) \theta}$. By evaluating at $\alpha=1$ we get:

$$
\begin{gathered}
\frac{\partial\left(\Delta C S\left(\varepsilon_{1}, \alpha=1, \theta\right)\right)}{\partial \alpha}=\frac{\theta}{\varepsilon_{1}\left(\varepsilon_{1}-1\right)}+\frac{1}{\varepsilon_{1}+\theta-1} \\
-\frac{1}{\varepsilon_{1}+\theta-1}\left(\frac{\varepsilon_{1}+\theta-1}{\varepsilon_{1}+\theta} \frac{\varepsilon_{1}}{\varepsilon_{1}-1}\right)^{\left(\varepsilon_{1}+\theta-1\right)} .
\end{gathered}
$$

We denote as $\underline{\underline{\theta}}\left(\varepsilon_{1}\right)$ the elasticity difference such that: $\frac{\partial\left(\Delta C S\left(\varepsilon_{1}, \alpha=1, \underline{\underline{\theta}}\left(\varepsilon_{1}\right)\right)\right)}{\partial \alpha}=$ 0 . So, it is satisfied 


$$
\frac{\partial\left(\Delta C S\left(\varepsilon_{1}, \alpha=1, \theta\right)\right)}{\partial \alpha}\left\{\begin{array}{ll}
>0 & \text { if } \theta<\underline{\bar{\theta}}\left(\varepsilon_{1}\right) \\
=0 & \text { if } \theta=\underline{\bar{\theta}}\left(\varepsilon_{1}\right) \\
<0 & \text { if } \theta>\underline{\underline{\theta}}\left(\varepsilon_{1}\right)
\end{array}\right\} .
$$

Given that the change in consumer surplus equals zero when the share of the strong market equals $1, \Delta C S\left(\varepsilon_{1}, \alpha=1, \theta\right)=0$, and given that $\frac{\partial\left(\Delta C S\left(\varepsilon_{1}, \alpha=1, \theta\right)\right)}{\partial \alpha}<0$ when $\theta>\underline{\underline{\theta}}\left(\varepsilon_{1}\right)$, then there exists a cutoff value $\overline{\bar{\alpha}} \equiv$ $\overline{\bar{\alpha}}\left(\varepsilon_{1}, \theta\right)>\bar{\alpha}$ such that if $\alpha>\overline{\bar{\alpha}}$ then the consumer surplus increases with price discrimination (or, in other terms, the output effect dominates the misallocation effect plus the increase in profits). Again the change in consumer surplus satisfies a single-crossing property and so we can state that when $\alpha<\overline{\bar{\alpha}}$ third-degree price discrimination reduces consumer surplus. Since price discrimination increases profits, necessarily $\underline{\underline{\theta}}\left(\varepsilon_{1}\right)>\underline{\theta}\left(\varepsilon_{1}\right)$ : in order to price discrimination to increase the consumer surplus the elasticity difference must be greater than the difference needed for price discrimination to increase social welfare. Numerical computations allow us to conclude that $\underline{\underline{\theta}}^{\prime}\left(\varepsilon_{1}\right)>0$. For example $\underline{\underline{\theta}}(1.5)=2.40912, \underline{\underline{\theta}}(2)=3.34766, \underline{\underline{\theta}}(3)=5.16996$ and $\underline{\underline{\theta}}(4)=6.97482$. Note that $\underline{\underline{\theta}}\left(\varepsilon_{1}\right)<\widetilde{\theta}\left(\varepsilon_{1}\right)$; for example, $\widetilde{\theta}(1.5)=4.4$, $\widetilde{\theta}(2)=7, \tilde{\theta}(3)=11.9$ and $\widetilde{\theta}(4)=16.9$.

The following proposition summarizes the results. It states that when the difference between demand elasticities is high enough (but compatible with Assumption 1) then there exists a cutoff value for the share of the strong markets above which third-degree price discrimination increases consumer surplus.

Proposition 3. If $\theta \in\left(\underline{\underline{\theta}}\left(\varepsilon_{1}\right), \widetilde{\theta}\left(\varepsilon_{1}\right)\right]$, then there exists a cutoff value $\overline{\bar{\alpha}} \equiv$ $\overline{\bar{\alpha}}\left(\varepsilon_{1}, \theta\right)>\bar{\alpha}\left(\varepsilon_{1}, \theta\right)$ such that:

(i) If $\alpha<\overline{\bar{\alpha}}$ then price discrimination reduces consumer surplus.

(ii) If $\alpha=\overline{\bar{\alpha}}$ then social welfare remains unchanged.

(iii) If $\alpha>\overline{\bar{\alpha}}$ then price discrimination increases consumer surplus.

Table 4 (see Appendix) illustrates the critical value for the share of market 1 under uniform pricing above which the consumer surplus increases with price discrimination. As expected, in order to increase consumer surplus we need a cutoff value for the share of market 1 higher than the one needed to increase welfare. 


\section{New upper and lower bounds on the change in social welfare under log-convex demand}

We next relate the change in consumer surplus due to a move from uniform pricing to price discrimination (see condition 24) to Varian (1985)'s upper bound (VUB) and lower bound (VLB) which under constant elasticity become:

$$
\begin{aligned}
V U B= & \left(p^{0}-c\right)\left(\Delta q_{1}+\Delta q_{2}\right)=(1-c)\left[\left(\frac{\left(\varepsilon_{1}-1\right)}{\varepsilon_{1}} \frac{1}{c}\right)^{\varepsilon_{1}}-1\right] \\
& +(1-c)\left[\left(\frac{\left(\varepsilon_{1}+\theta-1\right)}{\left(\varepsilon_{1}+\theta\right)} \frac{1}{c}\right)^{\varepsilon_{1}+\theta}-1\right] \\
V L B= & \left(p_{1}^{*}-c\right) \Delta q_{1}+\left(p_{2}^{*}-c\right) \Delta q_{2}=\frac{\alpha c}{\varepsilon_{1}-1}\left[\left(\frac{\left(\varepsilon_{1}-1\right)}{\varepsilon_{1}} \frac{1}{c}\right)^{\varepsilon_{1}}-1\right] \\
& +\frac{(1-\alpha) c}{\varepsilon_{1}+\theta-1}\left[\left(\frac{\left(\varepsilon_{1}+\theta-1\right)}{\left(\varepsilon_{1}+\theta\right)} \frac{1}{c}\right)^{\varepsilon_{1}+\theta}-1\right] .
\end{aligned}
$$

The next lemma shows that there are an upper bound and a lower bound to the change in consumer surplus for any log-convex demand functions which have decreasing marginal revenue. Constant elasticity demand satisfy both conditions.

Lemma 2. When demand functions are strictly log-convex and marginal revenues are strictly decreasing, the change in consumer surplus satisfies: $\left(p^{0}-c\right)\left(\Delta q_{1}+\Delta q_{2}\right)-\sum \pi_{i}^{\prime}\left(q_{i}^{0}\right) \Delta q_{i} \geq \Delta C S \geq \sum\left(p_{i}^{*}-c\right) \Delta q_{i}$, with strict

inequalities if $\Delta q_{i} \neq 0, i=1,2$.

Proof. Let consumer surplus as a function of quantity be $C S_{i}\left(q_{i}\right)=u_{i}\left(q_{i}\right)-$ $p_{i}\left(q_{i}\right) q_{i}$. It follows that $C S_{i}^{\prime}\left(q_{i}\right)=p_{i}\left(q_{i}\right)-r_{i}^{\prime}\left(q_{i}\right)$ where $r_{i}^{\prime}\left(q_{i}\right) \equiv p_{i}\left(q_{i}\right)+$ $q_{i} p_{i}^{\prime}\left(q_{i}\right)$ is marginal revenue and $C S_{i}^{\prime \prime}\left(q_{i}\right)=p_{i}^{\prime}\left(q_{i}\right)-r_{i}^{\prime \prime}\left(q_{i}\right)=r_{i}^{\prime \prime}\left(q_{i}\right)\left(\frac{p_{i}^{\prime}\left(q_{i}\right)}{r_{i}^{\prime \prime}\left(q_{i}\right)}-1\right)$. The expression $\frac{p_{i}^{\prime}\left(q_{i}\right)}{r_{i}^{\prime \prime}\left(q_{i}\right)}$ is the cost pass-through coefficient, and with strict logconvexity this exceeds 1 , so $C S_{i}^{\prime \prime}\left(q_{i}\right)<0$ (provided $\left.r_{i}^{\prime \prime}\left(q_{i}\right)<0\right)$. By concavity 
of consumer surplus in quantity, the change in aggregate consumer surplus is bounded above:

$$
\begin{aligned}
\Delta C S & \leq \sum C S_{i}^{\prime}\left(q_{i}^{0}\right) \Delta q_{i} \\
& =\sum\left(p_{i}\left(q_{i}^{0}\right)-r_{i}^{\prime}\left(q_{i}^{0}\right)\right) \Delta q_{i} \\
& =\sum\left(p_{i}\left(q_{i}^{0}\right)-c+c-r_{i}^{\prime}\left(q_{i}^{0}\right)\right) \Delta q_{i} \\
& =\left(p^{0}-c\right)\left(\Delta q_{1}+\Delta q_{2}\right)-\sum \pi_{i}^{\prime}\left(q_{i}^{0}\right) \Delta q_{i},
\end{aligned}
$$

and below:

$$
\begin{aligned}
\Delta C S & \geq \sum C S_{i}^{\prime}\left(q_{i}^{*}\right) \Delta q_{i} \\
& =\sum\left(p_{i}\left(q_{i}^{*}\right)-r_{i}^{\prime}\left(q_{i}^{*}\right)\right) \Delta q_{i} \\
& =\sum\left(p_{i}^{*}-c\right) \Delta q_{i} .
\end{aligned}
$$

This last expression follows because marginal revenue equals marginal cost with discrimination.

Remark. The lower bound for consumer surplus is the same as Varian's lower bound for welfare.

Lemma 2 can be used to provide conditions for consumer surplus to be higher with discrimination. It also provides tighter bounds for welfare than Varian's original bounds which is stated in the next proposition.

Proposition 4. When demand functions are strictly log-convex and marginal revenues are strictly decreasing, the change in welfare has an upper bound and a lower bound:

$$
\left(p^{0}-c\right)\left(\Delta q_{1}+\Delta q_{2}\right)-\sum \pi_{i}^{\prime}\left(q_{i}^{0}\right) \Delta q_{i}+\Delta \Pi \geq \Delta W \geq \sum\left(p_{i}^{*}-c\right) \Delta q_{i}+\Delta \Pi
$$

Proof. Add the change in profits, $\Delta \Pi$, to both sides of the inequalities in Lemma 1. 
The welfare lower bound in Lemma 2 is tighter than Varian's lower bound (because the change in profits is positive). The upper bound is also tighter than Varian's upper bound since the concavity of the profits functions guarantees $\Delta \Pi-\sum \pi_{i}^{\prime}\left(q_{i}^{0}\right) \Delta q_{i}<0 .{ }^{12}$ The change in profits, under constant elasticity demand, is given by:

$$
\Delta \Pi=\frac{\alpha c}{\varepsilon_{1}-1}\left(\frac{\left(\varepsilon_{1}-1\right)}{\varepsilon_{1}} \frac{1}{c}\right)^{\varepsilon_{1}}+\frac{(1-\alpha) c}{\varepsilon_{1}+\theta-1}\left(\frac{\left(\varepsilon_{1}+\theta-1\right)}{\left(\varepsilon_{1}+\theta\right)} \frac{1}{c}\right)^{\varepsilon_{1}+\theta}-(1-c),
$$

and given Varian's upper and lower bounds, see conditions (27) and (28), the new upper bound $(N U B)$ and lower bound $(N L B)$ are:

$$
\begin{aligned}
N U B= & \frac{\alpha}{\varepsilon_{1}}\left(\frac{\left(\varepsilon_{1}-1\right)}{\varepsilon_{1}} \frac{1}{c}\right)^{\varepsilon_{1}-1}\left(\frac{\left(\varepsilon_{1}-1\right)}{\varepsilon_{1}} \frac{1}{c}-1\right) \\
& +\frac{(1-\alpha)}{\varepsilon_{1}+\theta}\left(\frac{\left(\varepsilon_{1}+\theta-1\right)}{\left(\varepsilon_{1}+\theta\right)} \frac{1}{c}\right)^{\varepsilon_{1}+\theta-1}\left(\frac{\left(\varepsilon_{1}+\theta-1\right)}{\left(\varepsilon_{1}+\theta\right)} \frac{1}{c}-1\right) \\
& -\frac{\alpha}{\varepsilon_{1}}-\frac{(1-\alpha)}{\varepsilon_{1}+\theta}-\frac{1}{\varepsilon_{1}+(1-\alpha) \theta} \\
N L B= & \frac{\alpha c}{\varepsilon_{1}-1}\left[2\left(\frac{\left(\varepsilon_{1}-1\right)}{\varepsilon_{1}} \frac{1}{c}\right)^{\varepsilon_{1}}-1\right] \\
& +\frac{(1-\alpha) c}{\varepsilon_{1}+\theta-1}\left[2\left(\frac{\left(\varepsilon_{1}+\theta-1\right)}{\left(\varepsilon_{1}+\theta\right)} \frac{1}{c}\right)^{\varepsilon_{1}+\theta}-1\right]-(1-c) .
\end{aligned}
$$

Figure 3 represents the social welfare change, the Varian's upper and lower bounds and the new upper and lower bound when $\varepsilon_{1}=2$ and $\theta=4$.

\footnotetext{
${ }^{12}$ Note that the assumption $\varepsilon_{i}>1, i=1,2$, guarantees that the profit function in market $i$ (as a function of the output) is strictly concave under constant elasticity demand.
} 


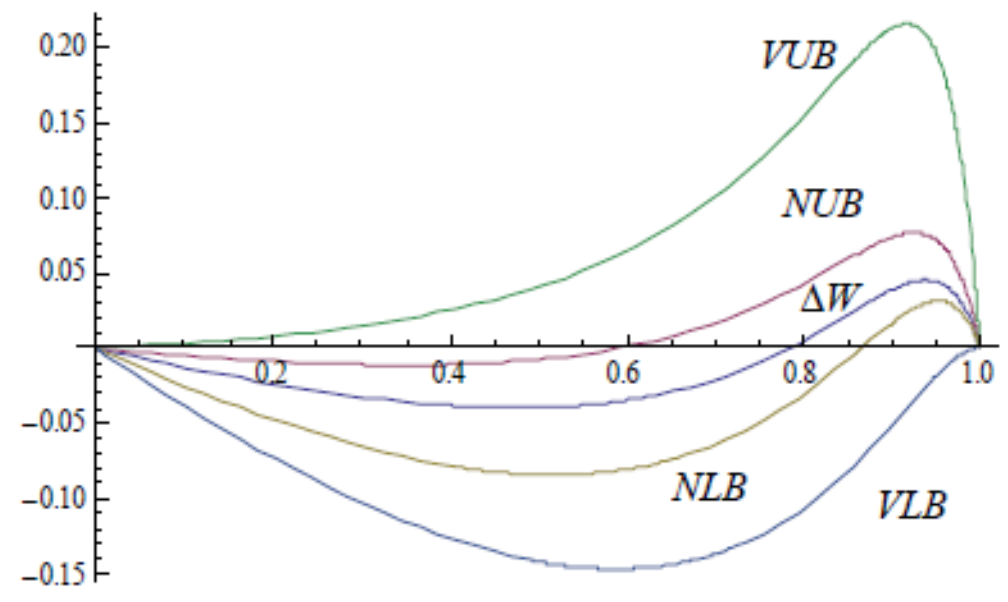

Figure 3. The change in social welfare $(\Delta W)$, the Varian's upper and lower bounds (VUB, VLB) and the new upper and lower bounds (NUB, NLB) when $\varepsilon_{1}=2$ and

$$
\theta=4 \text {. }
$$

\section{Concluding remarks}

The possibility that the output effect dominates the misallocation effect, something which would generate a welfare improvement, increases with the elasticity difference between the two markets and the share of the strong market under uniform pricing. The critical value of the share of market 1 (under single pricing) above which the output effect dominates the misallocation effect and, consequently, increases social welfare is a U-shaped function of the elasticity difference, the elasticity ratio and the pass-through ratio. The share of the strong market necessary for an increase of consumer surplus (of course, higher than that for an increase in welfare) is a decreasing function of the elasticity difference, the elasticity ratio and the pass-through ratio. We also generalize a property satisfied by constant elasticity demands to obtain new upper and lower bounds on social welfare when demand functions are log-convex. 


\section{APPENDIX}

\begin{tabular}{|c|c|c|c|c|c|c|c|c|c|}
\hline$\varepsilon_{1}$ & $\widetilde{\theta}\left(\varepsilon_{1}\right)$ & $\varepsilon_{1}$ & $\widetilde{\theta}\left(\varepsilon_{1}\right)$ & $\varepsilon_{1}$ & $\widetilde{\theta}\left(\varepsilon_{1}\right)$ & $\varepsilon_{1}$ & $\widetilde{\theta}\left(\varepsilon_{1}\right)$ & $\varepsilon_{1}$ & $\left.\widetilde{\theta}_{(1}\right)$ \\
\hline 1.1 & 2.1 & 3.1 & 12.5 & 5.1 & 22.3 & 7.1 & 32.1 & 9.1 & 41.9 \\
\hline 1.2 & 2.7 & 3.2 & 13 & 5.2 & 22.8 & 7.2 & 32.6 & 9.2 & 42.4 \\
\hline 1.3 & 3.3 & 3.3 & 13.5 & 5.3 & 23.3 & 7.3 & 33.1 & 9.3 & 42.8 \\
\hline 1.4 & 3.9 & 3.4 & 14 & 5.4 & 23.8 & 7.4 & 33.6 & 9.4 & 43.3 \\
\hline 1.5 & 4.4 & 3.5 & 14.5 & 5.5 & 24.3 & 7.5 & 34.1 & 9.5 & 43.8 \\
\hline 1.6 & 5 & 3.6 & 15 & 5.6 & 24.8 & 7.6 & 34.6 & 9.6 & 44.3 \\
\hline 1.7 & 5.5 & 3.7 & 15.5 & 5.7 & 25.2 & 7.7 & 35 & 9.7 & 44.8 \\
\hline 1.8 & 6 & 3.8 & 16 & 5.8 & 25.7 & 7.8 & 35.5 & 9.8 & 45.3 \\
\hline 1.9 & 6.5 & 3.9 & 16.4 & 5.9 & 26.2 & 7.9 & 36 & 9.9 & 45.8 \\
\hline 2 & 7 & 4 & 16.9 & 6 & 26.7 & 8 & 36.5 & 10 & 46.2 \\
\hline 2.1 & 7.5 & 4.1 & 17.4 & 6.1 & 27.2 & 8.1 & 37 & 10.1 & 46.7 \\
\hline 2.2 & 8 & 4.2 & 17.9 & 6.2 & 27.7 & 8.2 & 37.5 & 10.2 & 47.2 \\
\hline 2.3 & 8.5 & 4.3 & 18.4 & 6.3 & 28.2 & 8.3 & 38 & 10.3 & 47.7 \\
\hline 2.4 & 9 & 4.4 & 18.9 & 6.4 & 28.7 & 8.4 & 38.5 & 10.4 & 48.2 \\
\hline 2.5 & 9.5 & 4.5 & 19.4 & 6.5 & 29.2 & 8.5 & 38.9 & 10.5 & 48.7 \\
\hline 2.6 & 10 & 4.6 & 19.9 & 6.6 & 29.6 & 8.6 & 39.4 & 10.6 & 49.2 \\
\hline 2.7 & 10.5 & 4.7 & 20.4 & 6.7 & 30.1 & 8.7 & 39.9 & 10.7 & 49.7 \\
\hline 2.8 & 11 & 4.8 & 20.8 & 6.8 & 30.6 & 8.8 & 40.4 & 10.8 & 50.2 \\
\hline 2.9 & 11.5 & 4.9 & 21.3 & 6.9 & 31.1 & 8.9 & 40.9 & 10.9 & 50.7 \\
\hline 3 & 11.9 & 5 & 21.8 & 7 & 31.6 & 9 & 41.4 & 11 & 51.2 \\
\hline
\end{tabular}

Table 1. Critical elasticity difference as a function of elasticity in market 1 in order to guarantee that $p^{0}=1$ is the global maximizer. 


\section{Proof of Lemma 1}

(ii) We shall show that the second derivative of the change in social welfare, $\Delta W$, with respect to the share of the strong market, $\alpha$, satisfies the singlecrossing property which implies that the change in social welfare is a convexconcave function. The second derivative is given by:

$$
\begin{aligned}
& \frac{\partial^{2}\left(\Delta W\left(\varepsilon_{1}, \alpha, \theta\right)\right)}{\partial \alpha^{2}}=-\frac{2 \theta^{2}}{\left[\varepsilon_{1}+(1-\alpha) \theta\right]^{2}} \\
& +\frac{2 \alpha \theta^{2}\left(2 \varepsilon_{1}-1\right)\left(\varepsilon_{1}-1\right)}{\left(\varepsilon_{1}\right)^{2}\left[\varepsilon_{1}+(1-\alpha) \theta-1\right]^{3}}\left[\frac{\left(\varepsilon_{1}-1\right)}{\varepsilon_{1}} \frac{1}{c}\right]^{\left(\varepsilon_{1}-2\right)} \\
& +\frac{2(1-\alpha) \theta^{2}\left(2 \varepsilon_{1}+2 \theta-1\right)\left(\varepsilon_{1}+\theta-1\right)}{\left(\varepsilon_{1}+\theta\right)^{2}\left[\varepsilon_{1}+(1-\alpha) \theta-1\right]^{3}}\left[\frac{\left(\varepsilon_{1}+\theta-1\right)}{\varepsilon_{1}+\theta} \frac{1}{c}\right]^{\left(\varepsilon_{1}+\theta-2\right)} \\
& +\frac{2\left(2 \varepsilon_{1}-1\right)}{\varepsilon_{1}}\left(\frac{\varepsilon_{1}-1}{\varepsilon_{1}} \frac{\theta}{\left[\varepsilon_{1}+(1-\alpha) \theta-1\right]^{2}}\right)\left[\frac{\left(\varepsilon_{1}-1\right)}{\varepsilon_{1}} \frac{1}{c}\right]^{\left(\varepsilon_{1}-2\right)} \\
& +\frac{\alpha\left(\varepsilon_{1}-2\right)\left(2 \varepsilon_{1}-1\right)}{\varepsilon_{1}}\left(\frac{\varepsilon_{1}-1}{\varepsilon_{1}} \frac{\theta}{\left[\varepsilon_{1}+(1-\alpha) \theta-1\right]^{2}}\right)^{2}\left[\frac{\left(\varepsilon_{1}-1\right)}{\varepsilon_{1}} \frac{1}{c}\right]^{\left(\varepsilon_{1}-3\right)} \\
& -\frac{2\left(2 \varepsilon_{1}+2 \theta-1\right)}{\left(\varepsilon_{1}+\theta\right)}\left(\frac{\left(\varepsilon_{1}+\theta-1\right)}{\varepsilon_{1}+\theta} \frac{\theta}{\left[\varepsilon_{1}+(1-\alpha) \theta-1\right]^{2}}\right)\left[\frac{\left(\varepsilon_{1}+\theta-1\right)}{\varepsilon_{1}+\theta} \frac{1}{c}\right]^{\left(\varepsilon_{1}+\theta-2\right)} \\
& +\frac{(1-\alpha)\left(\varepsilon_{1}+\theta-2\right)\left(2 \varepsilon_{1}+2 \theta-1\right)}{\varepsilon_{1}}\left(\frac{\left(\varepsilon_{1}+\theta-1\right)}{\varepsilon_{1}+\theta} \frac{\theta}{\left[\varepsilon_{1}+(1-\alpha) \theta-1\right]^{2}}\right)^{2} \\
& {\left[\frac{\left(\varepsilon_{1}+\theta-1\right)}{\varepsilon_{1}+\theta} \frac{1}{c}\right]^{\left(\varepsilon_{1}+\theta-3\right)} \text {. }}
\end{aligned}
$$

It can be checked by numerical computations that $\frac{\partial^{2}\left(\Delta W\left(\varepsilon_{1}, \alpha, \theta\right)\right)}{\partial \alpha^{2}}$ crosses at most once the horizontal axis (we have checked numerically for $\varepsilon_{1} \in$ $\{1.5,2,3,4, \ldots, 11\}$, for any elasticity difference compatible with Assumption $1)$ : this guarantees that the change in social welfare is a convex-concave function of $\alpha$. 


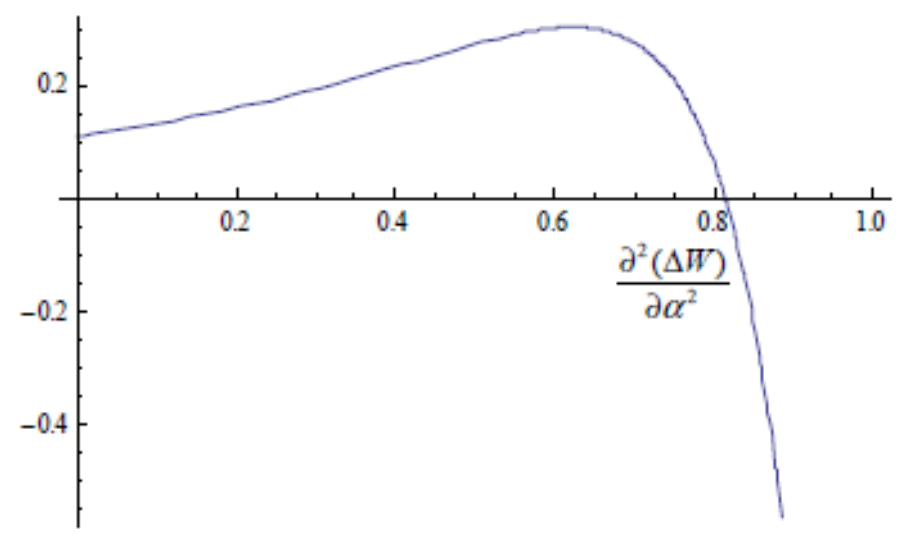

Figure 4. Second derivative of the change in social welfare as a function of $\alpha$ when $\varepsilon_{1}=2$ and $\theta=2$.

Figure 4 shows how the second derivative of the change in social welfare as a function of $\alpha$ (when $\varepsilon_{1}=2$ and $\theta=2$ ) satisfies a single-crossing property. Let $\widetilde{\alpha}\left(\varepsilon_{1}, \theta\right)$ be the share of the strong market such that $\frac{\partial^{2}\left(\Delta W\left(\varepsilon_{1}, \widetilde{\alpha}, \theta\right)\right)}{\partial \alpha^{2}}=0$ : that is, $\Delta W$ is a convex function for $\alpha<\widetilde{\alpha}$ and a concave function for $\alpha>\widetilde{\alpha}$. It is easy to check that: $\widetilde{\alpha}(2,0.6)=0.9958, \widetilde{\alpha}(2,1)=0.8656$, $\widetilde{\alpha}(2,1.5)=0.8221, \widetilde{\alpha}(2,2)=0.8147, \widetilde{\alpha}(2,3)=0.8291, \widetilde{\alpha}(2,4)=0.8525$, $\widetilde{\alpha}(2,5)=0.8757, \widetilde{\alpha}(2,6)=0.8967$ and $\widetilde{\alpha}(2,6.9)=0.9132$.

\section{Cross derivative}

The cross derivative is given by:

$$
\begin{gathered}
\frac{\partial^{2}\left(\Delta W\left(\varepsilon_{1}, \alpha=1, \theta\left(\varepsilon_{1}\right)\right)\right)}{\partial \alpha \partial \theta}=\frac{1}{\varepsilon_{1}\left(\varepsilon_{1}-1\right)}-\frac{1}{\left(\varepsilon_{1}+\theta-1\right)^{2}}-\frac{2 \Gamma}{\left(\varepsilon_{1}+\theta-1\right)\left(\varepsilon_{1}+\theta\right)} \\
+\frac{\left(2 \varepsilon_{1}+2 \theta-1\right) \Gamma}{\left(\varepsilon_{1}+\theta-1\right)\left(\varepsilon_{1}+\theta\right)^{2}}+\frac{\left(2 \varepsilon_{1}+2 \theta-1\right) \Gamma}{\left(\varepsilon_{1}+\theta-1\right)^{2}\left(\varepsilon_{1}+\theta\right)} \\
-\frac{\left(2 \varepsilon_{1}+2 \theta-1\right) \Gamma}{\left(\varepsilon_{1}+\theta-1\right)\left(\varepsilon_{1}+\theta\right)} \log \Gamma \\
-\frac{\left(2 \varepsilon_{1}+2 \theta-1\right) \Gamma\left(\varepsilon_{1}-1\right)\left(\varepsilon_{1}+\theta\right)}{\left(\varepsilon_{1}+\theta-1\right)\left(\varepsilon_{1}+\theta\right)}\left(-\frac{\left(\varepsilon_{1}+\theta-1\right)}{\left(\varepsilon_{1}-1\right)\left(\varepsilon_{1}+\theta\right)^{2}}+\frac{1}{\left(\varepsilon_{1}-1\right)\left(\varepsilon_{1}+\theta\right)}\right),
\end{gathered}
$$


where $\Gamma=\left(\frac{\varepsilon_{1}\left(\varepsilon_{1}+\theta-1\right)}{\left(\varepsilon_{1}-1\right)\left(\varepsilon_{1}+\theta-1\right)}\right)^{\varepsilon_{1}+\theta-1}$. We have checked numerically that $\frac{\partial^{2}\left(\Delta W\left(\varepsilon_{1}, \alpha=1, \theta\left(\varepsilon_{1}\right)\right)\right)}{\partial \alpha \partial \theta}\left\{\begin{array}{ll}>0 & \text { if } \theta<\widehat{\theta}\left(\varepsilon_{1}\right) \\ =0 & \text { if } \theta=\hat{\theta}\left(\varepsilon_{1}\right) \\ <0 & \text { if } \theta>\widehat{\theta}\left(\varepsilon_{1}\right)\end{array}\right\}$ where $\widehat{\theta}\left(\varepsilon_{1}\right)<\underline{\theta}\left(\varepsilon_{1}\right)$. Computations have been done for $\varepsilon_{1} \in\{1.5,2,3,4, \ldots, 11\}$ and for example $\widehat{\theta}(1.5)=$ $0.786891, \widehat{\theta}(2)=0.828747, \widehat{\theta}(3)=0.874788, \widehat{\theta}(4)=0.900631$, and so on. 


\begin{tabular}{|c|c|c|c|c|c|c|c|c|c|c|}
\hline$\theta \backslash \varepsilon_{1}$ & 1.5 & 2 & 3 & 4 & 5 & 6 & 7 & 8 & 9 & 10 \\
\hline 1.3 & 0.9909 & 1 & 1 & 1 & 1 & 1 & 1 & 1 & 1 & 1 \\
\hline 1.4 & 0.9701 & 0.9772 & 0.9889 & 0.9969 & 1 & 1 & 1 & 1 & 1 & 1 \\
\hline 2 & 0.8918 & 0.8811 & 0.8741 & 0.8720 & 0.8713 & 0.8711 & 0.8711 & 0.8712 & 0.8713 & 0.8715 \\
\hline 3 & 0.8364 & 0.8137 & 0.7924 & 0.7817 & 0.7753 & 0.7710 & 0.7679 & 0.7656 & 0.7638 & 0.7624 \\
\hline 4 & 0.8127 & 0.7851 & 0.7570 & 0.7418 & 0.7321 & 0.7254 & 0.7205 & 0.7167 & 0.7136 & 0.7112 \\
\hline 6 & & 0.7637 & 0.7295 & 0.7098 & 0.6966 & 0.6870 & 0.6798 & 0.6741 & 0.6695 & 0.6657 \\
\hline 7 & & 0.7598 & 0.7242 & 0.7033 & 0.6890 & 0.6786 & 0.6706 & 0.6642 & 0.6591 & 0.6548 \\
\hline 9 & & & 0.7203 & 0.6978 & 0.6822 & 0.6705 & 0.6614 & 0.6541 & 0.6481 & 0.6431 \\
\hline 12 & & & 0.7213 & 0.6977 & 0.6810 & 0.6683 & 0.6582 & 0.6500 & 0.6431 & 0.6373 \\
\hline 16 & & & & 0.7025 & 0.6851 & 0.6717 & 0.6609 & 0.6520 & 0.6444 & 0.6380 \\
\hline 21 & & & & 0.7101 & 0.6926 & 0.6788 & 0.6676 & 0.6582 & 0.6502 & 0.6432 \\
\hline 26 & & & & & & 0.6863 & 0.6749 & 0.6653 & 0.6570 & 0.6498 \\
\hline 31 & & & & & & & 0.6820 & 0.6722 & 0.6638 & 0.6565 \\
\hline 36 & & & & & & & & 0.6788 & 0.6703 & 0.6628 \\
\hline 41 & & & & & & & & & 0.6763 & 0.6688 \\
\hline 46 & & & & & & & & & & 0.6744 \\
\hline
\end{tabular}

Table 2. Critical value of the share of market 1 under uniform pricing, $\bar{\alpha}\left(\varepsilon_{1}, \theta\right)$, above which the output effect is stronger than the misallocation effect. 


\begin{tabular}{|c|c|c|c|c|c|c|c|c|c|}
\hline$\varepsilon_{1}$ & $\varepsilon_{2}$ & $\beta\left(\varepsilon_{1}\right)$ & $P_{1}(c) / P_{2}(c)$ & $\overline{\boldsymbol{\alpha}}$ & $\varepsilon_{1}$ & $\varepsilon_{2}$ & $\beta\left(\varepsilon_{1}\right)$ & $P_{1}(c) / P_{2}(c)$ & $\overline{\boldsymbol{\alpha}}$ \\
\hline 1.5 & 2.8 & 1.8666 & 1.9285 & 0.9909 & 4 & 5.4 & 1.35 & 1.0864 & 0.9969 \\
\hline 1.5 & 2.9 & 1.9333 & 1.9655 & 0.9701 & 4 & 6 & 1.5 & 1.1111 & 0.8720 \\
\hline 1.5 & 3.5 & 2.3333 & 2.1428 & 0.8918 & 4 & 7 & 1.75 & 1.1428 & 0.7817 \\
\hline 1.5 & 4.5 & 3 & 2.3333 & 0.8364 & 4 & 8 & 2 & 1.1666 & 0.7418 \\
\hline 1.5 & 5.5 & 3.6666 & 2.4545 & 0.8127 & 4 & 10 & 2.5 & 1.2 & 0.7098 \\
\hline 2 & 3.4 & 1.7 & 1.4117 & 0.9772 & 4 & 11 & 2.75 & 1.2121 & 0.7033 \\
\hline 2 & 4 & 2 & 1.5 & 0.8811 & 4 & 13 & 3.25 & 1.2307 & 0.6978 \\
\hline 2 & 5 & 2.5 & 1.6 & 0.8137 & 4 & 16 & 4 & 1.25 & 0.6977 \\
\hline 2 & 6 & 3 & 1.6666 & 0.7851 & 4 & 20 & 5 & 1.2666 & 0.7025 \\
\hline 2 & 8 & 4 & 1.75 & 0.7637 & 5 & 7 & 1.4 & 1.0714 & 0.8713 \\
\hline 2 & 9 & 4.5 & 1.7777 & 0.7598 & 5 & 8 & 1.6 & 1.0937 & 0.7753 \\
\hline 3 & 4.4 & 1.4666 & 1.1590 & 0.9889 & 5 & 9 & 1.8 & 1.1111 & 0.7321 \\
\hline 3 & 5 & 1.6666 & 1.2 & 0.8741 & 5 & 11 & 2.2 & 1.1363 & 0.6966 \\
\hline 3 & 6 & 2 & 1.25 & 0.7924 & 5 & 12 & 2.4 & 1.1458 & 0.6890 \\
\hline 3 & 7 & 2.3333 & 1.2857 & 0.7570 & 5 & 14 & 2.8 & 1.1607 & 0.6822 \\
\hline 3 & 9 & 3 & 1.3333 & 0.7295 & 5 & 17 & 3.4 & 1.1764 & 0.6810 \\
\hline 3 & 10 & 3.3333 & 1.35 & 0.7242 & 5 & 21 & 4.2 & 1.1904 & 0.6851 \\
\hline 3 & 12 & 4 & 1.375 & 0.7203 & 5 & 26 & 5.2 & 1.2019 & 0.6926 \\
\hline 3 & 15 & 5 & 1.4 & 0.7213 & & & & & \\
\hline
\end{tabular}




\begin{tabular}{|c|c|c|c|c|c|c|c|c|c|}
\hline$\varepsilon_{1}$ & $\varepsilon_{2}$ & $\beta\left(\varepsilon_{1}\right)$ & $P_{1}(c) / P_{2}(c)$ & $\overline{\boldsymbol{\alpha}}$ & $\varepsilon_{1}$ & $\varepsilon_{2}$ & $\beta\left(\varepsilon_{1}\right)$ & $P_{1}(c) / P_{2}(c)$ & $\overline{\boldsymbol{\alpha}}$ \\
\hline 6 & 8 & 1.3333 & 1.05 & 0.8711 & 8 & 14 & 1.75 & 1.0612 & 0.6741 \\
\hline 6 & 9 & 1.5 & 1.0666 & 0.7710 & 8 & 15 & 1.875 & 1.0666 & 0.6642 \\
\hline 6 & 10 & 1.6666 & 1.08 & 0.7254 & 8 & 17 & 2.125 & 1.0756 & 0.6541 \\
\hline 6 & 12 & 2 & 1.1 & 0.6870 & 8 & 20 & 2.5 & 1.0857 & 0.6500 \\
\hline 6 & 13 & 2.1666 & 1.1076 & 0.6786 & 8 & 24 & 3 & 1.0952 & 0.6520 \\
\hline 6 & 15 & 2.5 & 1.12 & 0.6705 & 8 & 29 & 3.625 & 1.1034 & 0.6582 \\
\hline 6 & 18 & 3 & 1.1333 & 0.6683 & 8 & 34 & 4.25 & 1.1092 & 0.6653 \\
\hline 6 & 22 & 3.6666 & 1.1454 & 0.6717 & 8 & 39 & 4.875 & 1.1135 & 0.6722 \\
\hline 6 & 27 & 4.5 & 1.1555 & 0.6788 & 8 & 44 & 5.5 & 1.1168 & 0.6788 \\
\hline 6 & 32 & 5.3333 & 1.1625 & 0.6863 & 9 & 11 & 1.2222 & 1.0227 & 0.8713 \\
\hline 7 & 9 & 1.2857 & 1.0370 & 0.8711 & 9 & 12 & 1.3333 & 1.0312 & 0.7638 \\
\hline 7 & 10 & 1.4285 & 1.05 & 0.7679 & 9 & 13 & 1.4444 & 1.0384 & 0.7136 \\
\hline 7 & 11 & 1.5714 & 1.0606 & 0.7205 & 9 & 15 & 1.6667 & 1.05 & 0.6695 \\
\hline 7 & 13 & 1.8571 & 1.0769 & 0.6798 & 9 & 16 & 1.7777 & 1.0546 & 0.6591 \\
\hline 7 & 14 & 2 & 1.0833 & 0.6706 & 9 & 18 & 2 & 1.0625 & 0.6481 \\
\hline 7 & 16 & 2.2857 & 1.0937 & 0.6614 & 9 & 21 & 2.3333 & 1.0714 & 0.6431 \\
\hline 7 & 19 & 2.7142 & 1.1052 & 0.6582 & 9 & 25 & 2.7777 & 1.08 & 0.6444 \\
\hline 7 & 23 & 3.2857 & 1.1159 & 0.6609 & 9 & 30 & 3.3333 & 1.0875 & 0.6502 \\
\hline 7 & 28 & 4 & 1.125 & 0.6676 & 9 & 35 & 3.8888 & 1.0928 & 0.6570 \\
\hline 7 & 33 & 4.7142 & 1.1313 & 0.6749 & 9 & 40 & 4.4444 & 1.0968 & 0.6638 \\
\hline 7 & 38 & 5.4285 & 1.1359 & 0.6820 & 9 & 45 & 5 & 1.1 & 0.6703 \\
\hline 8 & 10 & 1.25 & 1.0285 & 0.8712 & 9 & 50 & 5.5555 & 1.1025 & 0.6763 \\
\hline 8 & 11 & 1.375 & 1.0389 & 0.7656 & & & & & \\
\hline 8 & 12 & 1.5 & 1.0476 & 0.7167 & & & & & \\
\hline
\end{tabular}

Table 3. Critical value of the share of market 1 under uniform pricing, $\bar{\alpha}\left(\varepsilon_{1}, \theta\right)$, as function of the elasticity ratio, $\beta\left(\varepsilon_{1}\right)=\varepsilon_{2} / \varepsilon_{1}$ and the pass-through ratio. 


\begin{tabular}{|c|c|c|c|c|c|c|c|c|c|c|}
\hline$\theta \backslash \varepsilon_{1}$ & 1.5 & 2 & 3 & 4 & 5 & 6 & 7 & 8 & 9 & 10 \\
\hline 1.3 & 1 & 1 & 1 & 1 & 1 & 1 & 1 & 1 & 1 & 1 \\
\hline 1.4 & 1 & 1 & 1 & 1 & 1 & 1 & 1 & 1 & 1 & 1 \\
\hline 2 & 1 & 1 & 1 & 1 & 1 & 1 & 1 & 1 & 1 & 1 \\
\hline 3 & 0.9635 & 1 & 1 & 1 & 1 & 1 & 1 & 1 & 1 & 1 \\
\hline 4 & 0.9274 & 0.9674 & 1 & 1 & 1 & 1 & 1 & 1 & 1 & 1 \\
\hline 6 & & 0.9144 & 0.9712 & 1 & 1 & 1 & 1 & 1 & 1 & 1 \\
\hline 7 & & 0.9003 & 0.9462 & 0.9992 & 1 & 1 & 1 & 1 & 1 & 1 \\
\hline 9 & & & 0.9143 & 0.9528 & 0.9946 & 1 & 1 & 1 & 1 & 1 \\
\hline 12 & & & 0.8884 & 0.9144 & 0.9435 & 0.9745 & 1 & 1 & 1 & 1 \\
\hline 16 & & & & 0.8878 & 0.9075 & 0.9290 & 0.9517 & 0.9753 & 1 & 1 \\
\hline 21 & & & & & 0.8838 & 0.8987 & 0.9147 & 0.9315 & 0.9489 & 0.9667 \\
\hline 26 & & & & & & 0.8814 & 0.8933 & 0.9060 & 0.9192 & 0.9330 \\
\hline 31 & & & & & & & 0.8798 & 0.8897 & 0.9001 & 0.9111 \\
\hline 36 & & & & & & & & 0.8786 & 0.8871 & 0.8960 \\
\hline 41 & & & & & & & & & 0.8777 & 0.8851 \\
\hline 46 & & & & & & & & & & 0.8770 \\
\hline
\end{tabular}

Table 4. Critical value of the share of market 1 under uniform pricing, $\overline{\bar{\alpha}}\left(\varepsilon_{1}, \theta\right)$, above which price discrimination increases consumer surplus.

\section{References}

Aguirre, Iñaki. 2006. "Monopolistic Price Discrimination and Output Effect Under Conditions of Constant Elasticity Demand." Economics Bulletin, vol. 4, No 23 pp. 1-6.

Aguirre, Iñaki. 2008. "Output and Misallocation Effects in Monopolistic Third-Degree Price Discrimination." Economics Bulletin, vol. 4, No 11 pp. $1-11$.

Aguirre, Iñaki, Simon Cowan and John Vickers. 2010. "Monopoly Price Discrimination and Demand Curvature." American Economic Review 100 (4), pp. 1601-1615.

Bertoletti, Paolo. 2004. "A note on third-degree price discrimination and output". Journal of Industrial Economics, vol. 52, No 3, 457; available at the "Journal of Industrial Economics (JIE) Notes and Comments page", http:www.essex.ac.uk/jindec/notes.htm. 
Bulow, Jeremy, and Paul Klemperer. 2012. "Regulated Prices, Rent Seeking, and Consumer Surplus." Journal of Political Economy, 120 (1), 160186.

Cheung, Francis, and Xinghe Wang. 1994. "Adjusted Concavity and the Output Effect under Monopolistic Price Discrimination." Southern Economic Journal, 60(4): 1048-1054.

Cowan, Simon. 2007. "The Welfare Effects of Third-Degree Price Discrimination with Nonlinear Demand Functions." Rand Journal of Economics, 32(2): 419-428.

Cowan, Simon. 2012. "Third-Degree Price Discrimination and Consumer Surplus." Journal of Industrial Economics, LX: 333-345.

Edwards, Edgar O. 1950. "The analysis of output under discrimination." Econometrica, vol. 18: 163-172.

Formby, John P., Stephen Layson and W. James Smith. 1983. "Price Discrimination, Adjusted Concavity, and Output Changes Under Conditions of Constant Elasticity." Economic Journal, 93: 892-899.

Greenhut, Melvin L. and Hiroshi Ohta. 1976. "Joan Robinson's Criterion for Deciding Whether Market Discrimination Reduces Output." Economic Journal, 86: 96-97.

Ippolito, Richard. 1980. "Welfare Effects of Price Discrimination When Demand Curves are Constant Elasticity." Atlantic Economic Journal, 8: 8993.

Leontief, Wassily. 1940. "The Theory of Limited and Unlimited Discrimination." Quarterly Journal of Economics, 54(3): 490-501.

Nahata, Babu, Krzysztof Ostaszewski and Prasanna K. Sahoo. 1990. "Direction of Price Changes in Third-Degree Price Discrimination." American Economic Review, 80(5), 1254-1262.

Pigou, Arthur C. 1920. The Economics of Welfare, London: Macmillan, Third Edition.

Quah, John K.-H. and Bruno Strulovici. 2012. "Aggregating the single crossing property." Econometrica, vol. 80 (5), 2333-2348.

Robinson, Joan. 1933. The Economics of Imperfect Competition, London: Macmillan.

Schmalensee, Richard. 1981. "Output and Welfare Implications of Monopolistic Third-Degree Price discrimination." American Economic Review, 71(1): 242-247.

Schwartz, Marius. 1990. "Third-Degree Price Discrimination and Output: Generalizing a Welfare Result." American Economic Review, 80(5): 1259- 
1262.

Shih, Jun-ji, Chao-cheng Mai and Jung-chao Liu. 1988. "A General Analysis of the Output Effect under Third-Degree Price Discrimination." Economic Journal, 98 (389): 149-158.

Silberberg, Eugene. 1970. "Output under Discrimination: a Revisit." Southern Journal of Economics, 37(1): 84-87.

Smith, W. James and John P. Formby. 1981. "Output Changes Under Third-Degree Price Discrimination: A Re-examination." Southern Economic Journal, vol. 48: 164-171.

Varian, Hal R. 1985. "Price Discrimination and Social Welfare." American Economic Review, 75(4): 870-875.

Varian, Hal R. 1989. "Price Discrimination,"in R. Schmalensee and R. Willig (eds) Handbook of Industrial Organization: Volume I, North-Holland, Amsterdam.

Weyl, E. Glen and Michal Fabinger. 2013. "Pass-Through as an Economic Tool: Principles of Incidence Under Imperfect Competition." Journal of Political Economy, vol. 121 (3): 528-583. 